\title{
Ethics committees and the legality of research
}

\section{T M Douglas}

J Med Ethics 2007;33:732-736. doi: 10.1136/jme.2007.020479

One role of research ethics committees (RECs) is to assess the ethics of proposed health research. In some countries, RECs are also instructed to assess its legality. However, in other countries they are explicitly instructed not to do so. In this paper, I defend the claim that public policy should instruct RECs not to assess the legality of proposed research ("the Claim"). I initially defend a presumption in favour of the Claim, citing reasons for making research institutions solely responsible for assessing the legality of their own research. I then consider three arguments against the Claim which may over-ride this presumption-namely, that policy should instruct RECs to assess the legality of research because (1) doing so would minimise the costs of assessing the legality of research, (2) whether research is legal may partly determine whether it is ethical and (3) whether research is legal may constitute evidence for whether it is ethical. I reject the first two arguments and note that whether the third succeeds depends on the answer to a more fundamental question about the appropriate nature of REC ethical deliberation. I end with a brief discussion of this question, tentatively concluding that the third argument also fails.

Correspondence to: Thomas Douglas, Oxford Uehiro Center for Practical Ethics, University of Oxford, Littlegate House, St Ebbes Street, Oxford OXI 1PT, UK; thomas.douglas@ philosophy.ox.ac.uk

Received 22 January 2007

Revised 5 April 2007

Accepted 1 May 2007
$\mathrm{U}$ ntil the 1980s, the ethical regulation of health research was largely an informal process carried out within the research community. Research ethics committees (RECs) could be found, but they were generally the projects of research institutions or research funders. However, in many developed countries, these relatively informal arrangements have developed into a government-mandated regulatory structure: research proposals are assessed by RECs that are independent of research institutions and have formal operating guidelines and statutory responsibilities.

The same cannot be said regarding the legal assessment of health research proposals. Health researchers are open to court proceedings and criminal and civil sanctions. But there are generally no external procedures for assessing the legality of a research project before it takes place.

Given the presence of a government-mandated ethical review process for research proposals, the lack of any equivalent legal review process seems odd. After all, governments are typically more concerned to enforce legal standards than ethical ones. The obvious policy response to this apparent anomaly would be to require RECs to assess the legality, as well as the ethics, of proposed research, and some countries have pursued this option. In Australia, for example, RECs were, until this year, instructed not to approve a research proposal unless they were satisfied that the research would be lawful. ${ }^{12}$ And in some other jurisdictions, including New Zealand and Canada, public policy, though unclear, could be read as requiring some kind of legal review. ${ }^{3-5}$

In the United Kingdom, however, public policy explicitly instructs RECs not to assess the legality of proposed research, ${ }^{6}$ and there is something to be said for this approach, for where public policy instructs RECs to assess legality, or where it is unclear, legal review may cause considerable confusion and delay. The recent experience of New Zealand is instructive.

\section{THE NEW ZEALAND CERVICAL SCREENING AUDIT}

In November 1999, a group of researchers submitted for REC review a proposal for an audit and associated follow-up study of New Zealand's National Cervical Screening Programme. The work had been commissioned by the Ministry of Health and was prompted by evidence of systematic errors in the interpretation of cervical smear samples in one region of the country and of consequent delays in the diagnosis of cervical cancer in several women. It was hoped that the audit would clarify whether the misreporting of cervical smears was a nationwide problem, a matter under consideration by a Ministerial Inquiry at the time. ${ }^{7}$

As part of their audit, the researchers planned to access some identifiable information held on the New Zealand Cancer Register. A dispute regarding the legality of such information collection ensued, in the course of which the RECs sought assurances from various parties that the research would be lawful. Indeed, they went as far as to seek, unsuccessfully, a declarative judgement from the courts on the matter. ${ }^{8}$ When, 10 months after the initial submission, the research proposal had not been approved, the researchers withdrew the proposal, and the audit as originally conceived was never completed. The Ministerial Inquiry was critical of the role played by RECs in delaying the completion of the potentially life-saving research, but the RECs appear to have felt hamstrung by their inability to obtain a satisfactory legal opinion. ${ }^{78}$

Given the potential for legal review to impede important research and frustrate RECs, it is not obvious that public policy should instruct RECs to assess the legality of research. Moreover, since research governance arrangements are currently, or have recently been, under review in a number of countries, it seems timely to consider the various

Abbreviation: REC, research ethic committee 
policy options. ${ }^{2}{ }^{69}$ In what follows, I ask whether public policy should instruct RECs to assess the legality of research, or whether it should instead instruct them not to. I take it as read that public policy should issue clear instructions one way or the other. The lack of any such instructions in New Zealand seems to have contributed to the delays in the abovementioned case, with the Ministry of Health insisting that RECs were not required to assess legality, and the RECs proceeding on the opposite supposition. ${ }^{8}$

\section{SOME QUALIFICATIONS}

Before attempting to answer my primary question, however, I should make the following qualifications.

First, my question is a narrowly focused one about whether RECs should be instructed to assess the legality of proposed research. In particular, I do not ask whether RECs should be instructed to assess the legality of their own actions, nor whether they should be held legally liable for those actions.

Second, I intend my arguments to apply only to RECs whose ethical assessments are mandated by the government and whose caseload includes proposals from research institutions which have no jurisdiction over those committees. Examples of such committees would include the UK's local RECs and New Zealand's regional ethics committees. There are, however, many RECs that fall beyond the scope of my argument. These would include, for example, internal RECs set up voluntarily by research institutions in order to assess their own research proposals before forwarding them on for government-mandated ethical review. I take it that whether such RECs should be instructed to assess the legality of proposed research is a question for the institutions that host them, not for public policymakers. I also exclude from the scope of the analysis RECs whose primary task is not the assessment of research proposals. This category would include those committees whose primary task is to identify ethical principles for the regulation of health research and/or to advise on research governance arrangements-for example, the Australian Health Ethics Committee and Canada's Interagency Advisory Panel on Research Ethics.

Third, in asking whether RECs should be instructed to assess the legality of proposed research, I am simply asking whether they should determine whether that research is inconsistent with the relevant law. But I have in mind here a restricted understanding of "the relevant law". I exclude from this category those statutes, terms of reference and operating guidelines that govern REC procedure. Since these regulations just are the instructions issued to RECs, it is trivial both that RECs should comply with them and that they need not be separately instructed to do so. I also exclude from "the relevant law" codes of ethical practice such as the CIOMS guidelines, ${ }^{10}$ the Helsinki declaration, ${ }^{11}$ and the ethical codes of individual research institutions and medical associations. Since these codes are statements of ethical principles, it would be difficult to distinguish the task of ensuring that research complies with such codes from the task of assessing the ethics of research. We are thus left with the wide range of law that has a bearing on research but comprises neither ethical codes nor the instructions issued to ethics committees. This category will include many of the most familiar kinds of law-for example, criminal law, privacy law, intellectual property law, environmental law and employment law.

Finally, I will assume that the legality of research is conceptually distinct from the ethics of that research. This assumption should, I think, be uncontroversial-though ethics and law may be closely intertwined, most of us think that it makes sense to ask of a legal (or illegal) practice whether it is ethical (or unethical) and vice versa. But it must be distinguished from the less plausible view that the legality and ethics of research can be assessed independently of one another. This might be denied, for example, by those who believe that there is a moral obligation to obey the law, and by those who believe that legal reasoning inevitably involves ethical reasoning. ${ }^{12}{ }^{13}$ I will return to the relationship between legal and ethical assessment below, but at present, we need not take a position on this matter.

With these qualifications in mind, we can now turn to our main question: should RECs be instructed to assess, or not to assess, the legality of proposed research?

\section{THE CLAIM}

I have alluded to one argument for instructing RECs to assess legality: there is an external review process for assessing the ethics of proposed research, so there should be a similar process for assessing the legality of that research, and the obvious means of instituting such a process would be to instruct RECs to conduct this legal assessment.

This argument assumes that what goes for ethical assessment should also go for legal assessment. However, there are important disanalogies between ethical and legal assessment that might be called upon to justify different arrangements for the two kinds of assessment. Perhaps the most obvious of these is that legal standards, but not ethical ones, are generally backed up by strong external sanctions. Thus, without an ethical review process, researchers would arguably have little incentive to ensure that their work was ethical. On the other hand, the strong sanctions imposed on illegal activity create a strong incentive for researchers to conduct their own legal assessment, and there may thus be little need for external legal review.

There are, moreover, arguments for instructing RECs not to assess legality. Again, I have alluded to one such argument: if RECs were to engage in legal assessment, this might delay important research. However, delays such as those experienced in New Zealand might be due in part to the fact that RECs are not, as they are normally constituted, in a position to easily assess the lawfulness of research; though RECs may be required to include legally trained members, they are not normally staffed and resourced in such a way that they can be expected to make well-informed predictions about the myriad ways in which health research may be unlawful. This situation could, presumably, be remedied. Funding to RECs could be increased to allow them to employ legal staff or to commission legal advice from beyond their ranks. (I assume that commissioning an external assessment would qualify, for our purposes, as "assessing the legality of research".) However, even then, we should expect that any process that involved both legal and ethical assessment would be more cumbersome than one that involved ethical assessment only.

There is also another, perhaps stronger, argument for instructing RECs not to assess the legality of research.

In most spheres of life we think that each person should be made solely responsible for ensuring that her conduct is legal. And a similar principle applies to institutions. (I use "responsible" in a non-moral sense here: a person or institution is responsible for doing some act when, and only when, instructed by the law, or public policy, to do it.) There are exceptions to this rule. We would not want to make children solely responsible for ensuring that their conduct is lawful-we think that their parents also bear at least a share of the responsibility. In addition, employers are sometimes deemed partly responsible for ensuring that their employees act in a lawful manner, and we need not find this problematic. But we generally take it that: 
In the absence of good countervailing reasons, each person (or institution) should be made solely responsible for ensuring the lawfulness and ethics of her (its) conduct.

This view appears to fit well with our moral intuitions, and there is also a rationale for accepting it. It can be argued that requiring individual parties to take responsibility for assessing the legal implications of their own actions helps to avoid regulatory costs: in a world where each party carefully considered the legal implications of her actions, there would be less expensive work for law enforcement agencies. This is not merely a matter of shifting costs from regulatory agencies to individuals. Individual parties will generally be in possession of much of the information about their actions necessary to conduct a legal assessment of those actions, thus, making each solely responsible for assessing the legality of her actions may minimise the information-gathering costs associated with preventing unlawful conduct.

It thus seems plausible that, in the absence of good countervailing reasons, researchers, or research institutions, should be made solely responsible for assessing the lawfulness of their research, and therefore that

\section{RECs should be instructed not to assess the legality of research (henceforth, "the Claim")}

In what follows, I consider three arguments which may override the considerations in favour of this claim.

\section{ARGUMENT 1: COST REDUCTION}

I suggested above that making individuals solely responsible for assessing the legality of their actions would minimise the costs of achieving legal compliance. But it might be wondered whether this is true in the case of health research, where responsibility for legal assessment could be assigned to RECs instead. In assessing the ethics of research proposals, RECs are likely to come across potentially illegal aspects of those proposals since when some aspect of proposed research is unethical, it is also likely to be illegal. Thus, we might think that RECs could identify potential legal issues at relatively little cost. Individual research institutions, on the other hand, might have to expend considerable time and effort in order to identify the same issues.

There are two problems with this suggestion, however. First, it assumes that research institutions do not have their own internal ethical review procedures to complement external ethical review arrangements. But many institutions do, or at least should, have such procedures. Thus, they may also be in a position to identify potential legal issues at little cost. Second, even if RECs could identify potential legal issues at a lower cost than research institutions, it would not necessarily follow that they should be instructed to assess the legality of research. The potential efficiency gains would be exhausted by simply requiring RECs to inform research institutions of any potential legal issues that they notice. Responsibility for pursuing those issues could be left with the research institutions.

Another efficiency-based reason for having RECs assess legality would be that a degree of centralisation in the legal assessment process might allow for economies of scale. For example, since health research law is a highly specialised area, individual research institutions might have to expend considerable effort identifying appropriate legal advisors each time a potentially problematic case arose. However, due to their high throughput of proposals, RECs would be able to form a relationship with an appropriate legal advisor, thus reducing the per-unit costs of seeking legal advice. But even if this were so, it would not follow that RECs should be instructed to actually assess the legality of research. The potential economies of scale could be attained by giving RECs an advisory role, whereby they inform research institutions when they believe that legal assessment might be warranted, and of whence such a legal assessment might be obtained.

\section{ARGUMENT 2: THE LAW AS AN ETHICAL CONSIDERATION}

A second argument against the Claim is based on the view, often discussed by moral and legal philosophers, that one has an ethical reason or obligation to obey the law. If one accepts this view, then it would seem that whether or not a proposed research practice is legal would be relevant to whether the practice is ethical; its being illegal would count against its being ethical. It might follow that RECs should be instructed to assess the legality of research as part of their ethical assessment process.

Moore notes that this argument contains a suppressed premise: that RECs should be instructed to assess all matters that bear on the ethics of proposed research. ${ }^{4}$ But intuitively, this premise is, as Moore notes, false: whether a research project constitutes a good use of a research institution's resources is surely relevant to its ethics, but we would not wish to instruct RECs to assess this. It thus seems that public policy should not instruct ethics committees to assess all matters that bear on the ethics of proposed research. Hence, the mere fact that the legality of research is ethically relevant would not justify instructing RECs to assess it.

One way of responding to Moore's objection would be to amend the original argument so that it no longer relies on the suppressed premise that Moore finds objectionable. Thus, we could accept that RECs should not be instructed to assess all ethically-relevant matters, while maintaining that the legality of research is one ethically relevant matter that they should be instructed to assess. RECs normally are instructed to assess whether, and to what extent, proposed research is likely to be harmful to research participants. And one way that research can harm participants is by either involving them in, or making them victims of, illegal activity. Thus, consider a case in which investigators would breach the bodily integrity of research participants without their consent. Here, participants would be the victims of illegal activity. And quite apart from any physical or psychological harms that might result from the actions of the researchers, one might think that the very breach of the participants' legal rights itself constitutes a kind of legal harm. It might, then, be argued that if RECs are to make a proper assessment of the extent to which research participants may be harmed by proposed research, they will need to arrive at a judgment as to whether that research is legal.

This argument is, however, susceptible to an amended version of Moore's original response. Just as we do not think RECs should be instructed to assess all ethically relevant matters, neither do we think that they should be instructed to assess all harms. For example, RECs should perhaps not assess whether research participants would be financially harmed by taking time off work to participate in research. So perhaps they should also not assess whether research participants would be victims of legal harms.

An alternative way of responding to Moore would be to defend the suppressed premise that Moore finds objectionable. It could be argued that, despite our intuitions to the contrary, RECs should be instructed to assess all matters bearing on the legality of proposed research, since they must form an overall ethical judgment as to whether that research should proceed, and for this judgment to be maximally accurate, it would have to be based on an assessment of all matters bearing on the ethics of the research proposal. However, even if we grant that 
RECs should form such an overall ethical judgment, it would not follow that they would need to assess all ethically relevant matters. Instead, some other body-perhaps the research institution itself-could be instructed to assess some of those matters (perhaps including the legality of research), making the results of its assessment available to the REC. The REC could then simply take these results as an input into its ethical assessment process.

\section{ARGUMENT 3: THE LAW AS ETHICAL EVIDENCE}

We have just considered the view that the legality of research partly determines its ethics. But there is another way in which the legality of research might be relevant to its ethics. It may be that if research would be illegal, that would constitute evidence for its being unethical. ${ }^{14}{ }^{15}$ It is relatively easy to tell a story about why the law might provide such evidence. For example, in democratic countries, we can perhaps think of the law as representing some sort of consensus as to the limits of ethically acceptable conduct, and arguably this consensus is likely to reflect the ethical truth of the matter.

Accepting that the law plays this evidential role, we could argue in the following fashion: when RECs deliberate about some research proposal, they ought to consider all of the evidence for and against that research being ethical; thus, they ought to consider whether that research is illegal.

There is, of course, room for disagreement over whether the law does in fact play an evidential role in ethical reasoning. Moreover, even if the law does play this role, it may not follow that RECs should be instructed to assess legality. It has been argued that RECs should rely on the ethical evidence provided by introspection, rather than that provided by social consensus. ${ }^{16}$ Furthermore, it is not obvious that RECs should be engaged in the sort of deliberation that involves the consideration of ethical evidence at all. To determine whether they should, we need to ask some deeper questions.

\section{THE DELIBERATIVE ROLE OF RESEARCH ETHICS COMMITTEES}

We can distinguish, at this point, between two varieties of ethical deliberation. One sort begins by identifying ethical principles and then proceeds to apply those principles to the question under consideration. Call this free deliberation. A second sort of deliberation takes a set of ethical principles as external inputs, and engages only in the principle-application phase. Call this constrained deliberation.

I take it that free deliberation is the sort of deliberation normally engaged in by academic ethicists. Suppose that there is a question as to whether stem cell research should be permitted. Academic deliberations on this question would no doubt begin with the identification of principles about, for example, the moral rights of embryos, and the moral reasons to advance stem cell research. Only then would these principles be applied.

It is less clear, however, that RECs should engage in free deliberation. Plausibly, they should, as far as possible, simply apply the ethical principles that they are instructed to apply. This view has important implications for our question, since in so far as RECs engage only in constrained deliberation, any evidential role played by the law will generally be irrelevant to their deliberations. The fact that proposed research would be illegal may constitute evidence that it would be unethical. But whether it is unethical is not the relevant question in constrained deliberation. The constrained deliberator asks only whether the practice in question is consistent with certain specified ethical principles, which may well be false or incomplete. And, except where the law happens to incorporate precisely those specified principles, assessing the legality of research will provide no evidence of relevance to this question.
It is difficult to make any firm pronouncements on whether RECs should engage predominantly in free or constrained deliberation. I will not make any here. However, let me note two considerations in favour of the constrained-deliberation view.

The first consideration draws on the fact that RECs exist only because health research poses some peculiarly difficult ethical issues. Arguably, these difficulties surround, primarily, the application of ethical principles. There is little reason to think that identifying ethical principles to govern health research is any more difficult than identifying ethical principles to govern any other practice. Indeed, the same fundamental principles can probably be applied to all areas of human activity. Certainly, most of the main schools of ethical thought—such as utilitarianism and Kantianism-assume this. It is only when we try to apply these general principles to issues in health research that the peculiar difficulties arise. This suggests that RECs are required only for their expertise in constrained deliberation.

The second consideration is that RECs arguably lack the democratic authority to engage in free deliberation. The ethical principles for governing health research within a given state should, presumably, be chosen by the citizens of that state or their representatives, and though RECs could be construed as quasi-representative bodies, they are less obviously representative than, for example, a democratically elected government. Plausibly, the identification of ethical principles for governing health research should be left up to such governments.

Further debate needs to be had on whether these considerations are decisive. But if they are, it would follow that RECs should not be in the business of collecting ethical evidence. The fact that legal assessments might yield such evidence would thus not undermine the Claim. And we would therefore, I suggest, be left without any good argument for over-riding the presumption in favour of instructing RECs not to assess the legality of proposed research.

\section{ACKNOWLEDGEMENTS}

I would like to thank Andrew Moore, Julian Savulescu and two anonymous reviewers for their comments on drafts of this paper. For their financial support, I thank the Wellcome Trust and the New Zealand Ministry of Health.

Funding: Wellcome Trust, New Zealand Ministry of Health (external contract). The views contained in the paper are the views of the author only.

Competing interests: None.

\section{REFERENCES}

1 National Health and Medical Research Council. National statement on ethical conduct in research involving humans. Canberra: Commonwealth of Australia, 1999:5.

2 National Health and Medical Research Council, Australian Research Council, Australian Vice-Chancellors' Committee, National Health and Medical Research Council. National statement on ethical conduct in human research, Canberra: Commonwealth of Australia, 2007.

3 Ministry of Health. Operational standard for ethics committees, Updated edn. Wellington: Ministry of Health, 2002.

4 Moore A. Research, ethics committees, and legal issues. NZ Bioeth J 2003;4:8-15.

5 Canadian Institutes of Health Research, Natural Sciences and Engineering Research Council of Canada, Social Sciences Research Council of Canada. Tricouncil policy statement: ethical conduct for research involving humans. Ottawa: Interagency Secretariat on Research Ethics, 2005.

6 Department of Health. Research governance framework for health and social care. 2nd ed. London: DH, 2005:37.

7 Duffy A, Barrett D, Duggan M. Report of the ministerial inquiry into the underreporting of cervical smear abnormalities in the Gisborne region. Wellington: Gisborne Cervical Screening Inquiry, 2001, http://www.csi.org.nz.

8 Evans D. Brief of Donald Morgan Evans in the matter of the Health and Disability Services Act 1993 and in the matter of a Ministerial Inquiry into the Underreporting of Cervical Smear Abnormalities in the Gisborne Region. 4 August 2000. http://www.csi.org.nz.

9 National Ethics Advisory Committee. Fourth annual report to the Minister of Health. Wellington: Ministry of Health, 2006.

10 Council for International Organizations of Medical Sciences. International Ethical Guidelines for Biomedical Research Involving Human Subjects. Geneva: ClOMS, 2002, http://www.cioms.ch. 
11 World Medical Association. Declaration of Helsinki: ethical principles for medical research involving human subjects. Helsinki: World Medical Association, 1964. http://www.wma.net.

12 Dworkin R. Taking rights seriously. London: Duckworth, 1977.

13 Dworkin R. Law's empire. Cambridge: Harvard University Press, 1986.
14 De Ville K, Hassler G. Healthcare ethics committees and the law: uneasy but inevitable bedfellows. HEC Forum 2001;13:13-31.

15 Raz J. The authority of law: essays on law and morality. Oxford: Oxford University Press, 1979

16 Clarke S. Two models of ethics committees. J Bioeth Inq 2005;2:41-7.

\section{BMJ Clinical Evidence-Call for contributors}

BMJ Clinical Evidence is a continuously updated evidence-based journal available worldwide on the internet which publishes commissioned systematic reviews. BMJ Clinical Evidence needs to recruit new contributors. Contributors are healthcare professionals or epidemiologists with experience in evidence-based medicine, with the ability to write in a concise and structured way and relevant clinical expertise.

Areas for which we are currently seeking contributors:

- Secondary prevention of ischaemic cardiac events

- Acute myocardial infarction

- MRSA (treatment)

- Bacterial conjunctivitis

However, we are always looking for contributors, so do not let this list discourage you.

Being a contributor involves:

- Selecting from a validated, screened search (performed by in-house Information Specialists) valid studies for inclusion.

- Documenting your decisions about which studies to include on an inclusion and exclusion form, which we will publish.

- Writing the text to a highly structured template (about 1500-3000 words), using evidence from the final studies chosen, within 8-10 weeks of receiving the literature search.

- Working with BMJ Clinical Evidence editors to ensure that the final text meets quality and style standards.

- Updating the text every 12 months using any new, sound evidence that becomes available. The BMJ Clinical Evidence in-house team will conduct the searches for contributors; your task is to filter out high quality studies and incorporate them into the existing text.

- To expand the review to include a new question about once every 12 months.

In return, contributors will see their work published in a highly-rewarded peer-reviewed international medical journal. They also receive a small honorarium for their efforts.

If you would like to become a contributor for BMJ Clinical Evidence or require more information about what this involves please send your contact details and a copy of your CV, clearly stating the clinical area you are interested in, to CECommissioning@bmigroup.com.

\section{Call for peer reviewers}

BMJ Clinical Evidence also needs to recruit new peer reviewers specifically with an interest in the clinical areas stated above, and also others related to general practice. Peer reviewers are healthcare professionals or epidemiologists with experience in evidence-based medicine. As a peer reviewer you would be asked for your views on the clinical relevance, validity and accessibility of specific reviews within the journal, and their usefulness to the intended audience (international generalists and healthcare professionals, possibly with limited statistical knowledge). Reviews are usually 1500-3000 words in length and we would ask you to review between 2-5 systematic reviews per year. The peer review process takes place throughout the year, and our turnaround time for each review is 10-14 days. In return peer reviewers receive free access to BMJ Clinical Evidence for 3 months for each review.

If you are interested in becoming a peer reviewer for BMJ Clinical Evidence, please complete the peer review questionnaire at www. clinicalevidence.com/ceweb/contribute/peerreviewer.jsp 